\title{
Autonomic modulation of the atrial cycle length by the head up tilt test: non-invasive evaluation in patients with chronic atrial fibrillation
}

\author{
M P Ingemansson, M Holm, S B Olsson
}

\begin{abstract}
Objective-To determine the effects of upright posture compared with supine position on the dominant atrial cycle length (DACL) in patients with chronic atrial fibrillation.

Design-The power/frequency spectrum of QRST suppressed lead V1 ECG was studied in 14 patients in the supine position and during the head up tilt table test. The DACL changes were compared with changes in heart rate and blood pressure.

Results-Compared with the supine position, the upright position reduced the DACL from 160 to $150 \mathrm{~ms}(\mathrm{p}<0.01)$. The DACL was increased after returning to the supine position from the upright position, from 147 to $154 \mathrm{~ms}(p<0.01)$. Heart rate increased from 91 beats $/ \mathrm{min}$ in the supine position to 106 in the upright position $(p<0.01)$. There was a decrease in heart rate from 109 beats/min in the upright position to 93 after returning to the supine position $(p<0.01)$. No significant changes were seen in systolic or diastolic blood pressure. There were indications of an inverse relation between DACL and heart rate when comparing the supine position before and after tilt with the upright position $(\mathrm{p}<0.001)$.

Conclusions-The sympathetic stimulation and vagal withdrawal induced by rising to upright body position are associated with a decrease in DACL during chronic atrial fibrillation. Thus a reflex increase in sympathetic discharge after induction of atrial fibrillation could favour the persistence of the arrhythmia.

(Heart 1998;80:71-76)
\end{abstract}

Keywords: atrial fibrillation; autonomic nervous system; atrial cycle length; heart rate

The autonomic nervous system plays an important role in the genesis of various cardiac arrhythmias. The atrial muscle is continuously affected by the balance between vagal and sympathetic discharge. The influence of different kinds of autonomic discharge on the cellular electrophysiological properties of normal atrial muscle in both man and animal has been studied during sinus rhythm, but limited information is available on the conditions during chronic atrial fibrillation. ${ }^{1-7}$

Previous studies have shown that altered or disturbed autonomic tone may result in initia- tion of atrial fibrillation. ${ }^{8-11}$ It is well known that vagal stimulation increases vulnerability to atrial fibrillation by shortening the atrial refractory period, ${ }^{7}$ while increased sympathetic discharge is associated with automatism, triggered activity, and microreentry. ${ }^{12}$

Several in vitro studies have documented the existence of diseased, depolarised muscle with cellular electrophysiological and ultrastructural derangement, in strips obtained from the atrium of patients with chronic atrial fibrillation. ${ }^{13-19}$ These observations are supported by the findings of an electrical remodelling of the atrial muscle during exposure to tachycardia. ${ }^{20-23}$ The effects of vagal and sympathetic discharge on diseased, structurally changed atrial muscle are not well documented. In the normal heart, vagal tone is dominant at the atrial level during rest. ${ }^{6}$ However, sympathetic predominance and reduced vagal tone have been shown to accompany disease in ventricular muscle. ${ }^{24}$ The autonomic balance in chronic atrial fibrillation is complex and the ability of either autonomic nervous system limb to produce disturbances in atrial conduction, refractoriness, and the dispersion of atrial refractoriness needs further clarification.

This study aimed to investigate the influence of modulation of the autonomic nervous system, using the head up tilt test, on the dominant atrial cycle length (DACL) during chronic atrial fibrillation. The DACL measured at lead V1 is closely related to the spatial mean intracardiac cycle length in the right atrium. ${ }^{25}$ As the local atrial cycle length during chronic atrial fibrillation has been shown to be closely related to the atrial refractory period,

Table 1 Patient characteristics

\begin{tabular}{lllll}
\hline Case & $\begin{array}{l}\text { Age } \\
\text { (years) }\end{array}$ & Sex & $\begin{array}{l}\text { Chronic AF } \\
\text { associated disease }\end{array}$ & $\begin{array}{l}\text { AF duration } \\
\text { (months) }\end{array}$ \\
\hline 1 & 63 & $\mathrm{M}$ & HF & 1 \\
2 & 76 & $\mathrm{~F}$ & HT & 5 \\
3 & 67 & $\mathrm{M}$ & None & $>2$ \\
4 & 65 & $\mathrm{~F}$ & AS & 6 \\
5 & 68 & $\mathrm{~F}$ & None & 2 \\
6 & 50 & $\mathrm{~F}$ & None & $>12$ \\
7 & 71 & $\mathrm{M}$ & IHD, HT & $>12$ \\
8 & 64 & $\mathrm{~F}$ & None & 7 \\
9 & 69 & $\mathrm{M}$ & IHD & 3 \\
10 & 72 & $\mathrm{M}$ & None & 3 \\
11 & 76 & $\mathrm{M}$ & IHD, AS & 3 \\
12 & 69 & $\mathrm{~F}$ & None & $>12$ \\
$13^{\star}$ & 48 & $\mathrm{M}$ & HF, DCM & $>3$ \\
$14 \dagger$ & 67 & $\mathrm{M}$ & AS & $>5$ \\
\hline
\end{tabular}

«Patient 13 excluded because of syncope; tpatient 14 excluded because of multifocal atrial tachycardia.

AF, atrial fibrillation; AS, aortic stenosis; DCM, dilated cardiomyopathy; HT, hypertension; IHD, ischaemic heart disease; MVD, mitral valve disease. 


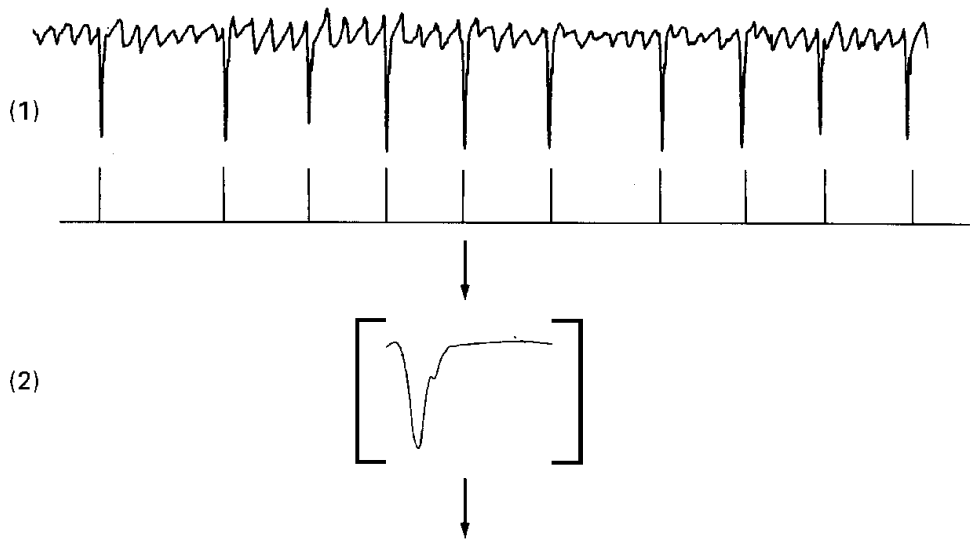

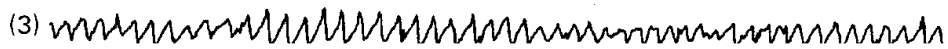

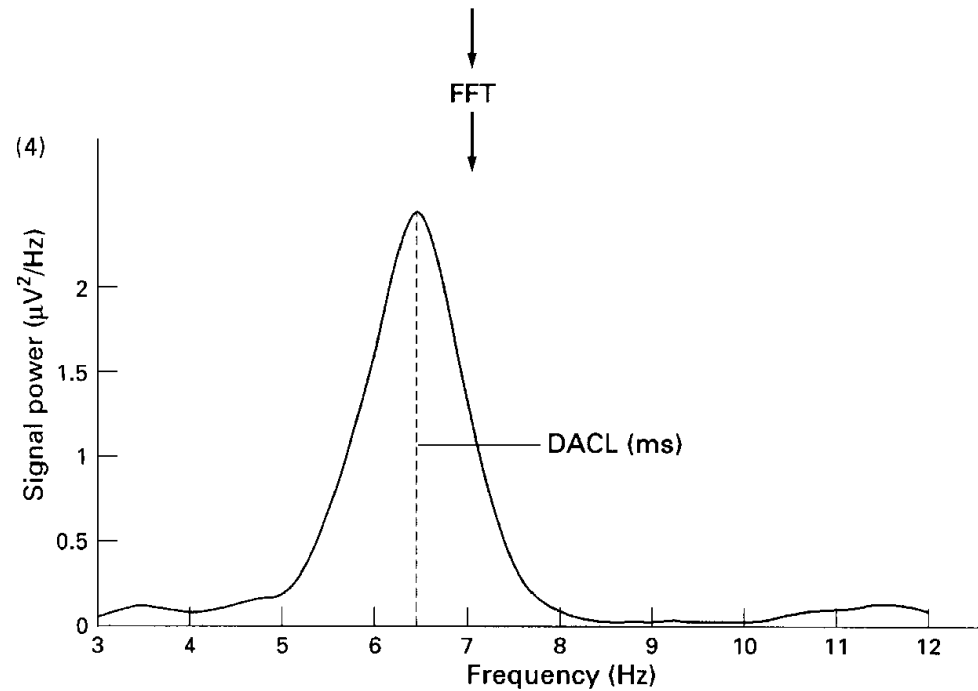

Figure 1 Schematic illustration of the different steps of the FAF-ECG method. (1) Low frequency components were reduced using a linear phase high pass filter. (2) Classification and subtraction of QRST complexes from the original ECG signal. (3) A frequency spectrum was estimated from the residual ECG signal using the fast Fourier transform technique (FFT). (4) The peak frequency of the dominating frequency components between 3 and $12 \mathrm{~Hz}$ was estimated, corresponding to the dominant atrial cycle length (DACL).

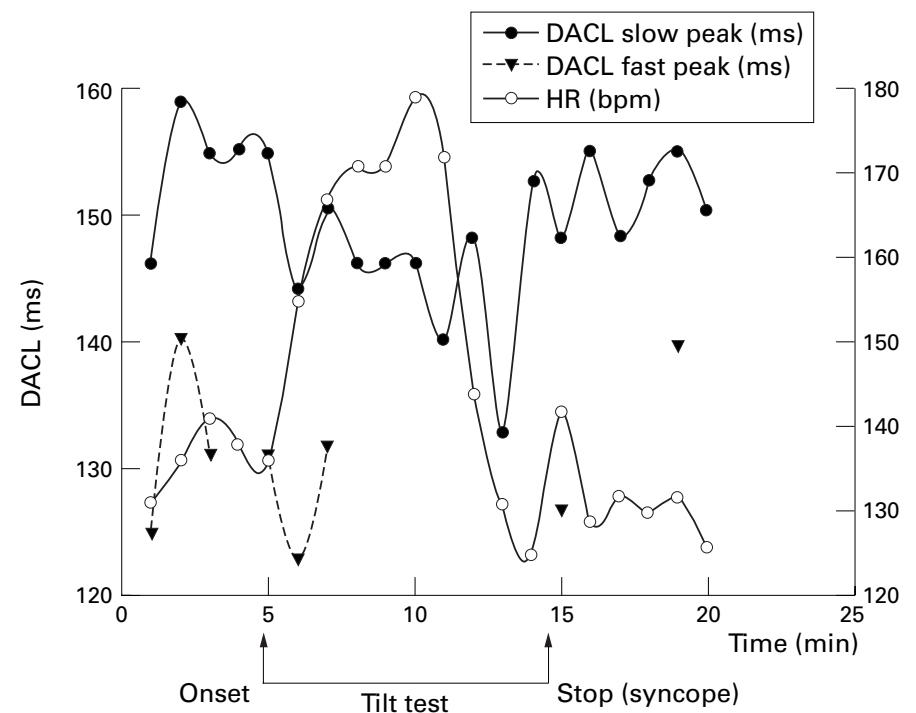

Figure 2 Relation of heart rate (HR) and dominant atrial cycle length (DACL) in the patient with syncope, obtained with one minute analysis intervals. The heart rate increased markedly after tilt onset and a rapid decline in both heart rate and DACL was observed before syncope, compatible with strong vagal discharge. The frequency signal had a bimodal appearance with two peaks. Note that the non-dominant peak disappears as the DACL decreases and returns after return to the supine position. the DACL was considered an index of right atrial refractoriness. ${ }^{26-28} \mathrm{~A}$ head up tilt table test was performed and the DACL was assessed using the non-invasive frequency analysis of fibrillatory ECG (FAF-ECG) method presented elsewhere. ${ }^{25}$

\section{Methods}

PATIENTS AND DESIGN OF THE TILT TEST

Fourteen patients (eight men and six women aged 48 to 76 years, median 67.5) with chronic atrial fibrillation were included in the study (table 1). The head up tilt test was performed between 09:00 and 16:00 in a quiet study room with dimmed lights. All cardioactive drugs were withdrawn at least five half lives before participation in the study. The tilt table used was manually operated, with foot board support. Before the start of recordings the patients rested for a 15 minute period. Thereafter, surface ECG was recorded digitally for a total of 25 minutes with (1) an initial five minute period of supine rest, (2) a 15 minute period of head up tilt to $80^{\circ}$, and (3) a final five minute period of supine rest (hardware supplied by Siemens-Elema, Solna, Sweden). Blood pressure was measured manually using a cuff sphygmomanometer every two minutes during the whole study period. Heart rate was determined from the surface ECG recording.

FREQUENCY ANALYSIS OF FIBRILLATORY ECG (FAF-ECG)

A new non-invasive method based on frequency analysis of the $f$ waves in the surface ECG was used (fig 1). The method is described in detail elsewhere. ${ }^{25}$ In short, the frequency distribution between 3 and $12 \mathrm{~Hz}$ in a QRST suppressed V1 lead ECG is estimated and the cycle length corresponding to the dominant frequency peak is named the dominant atrial cycle length (DACL). The changes in DACL induced by the head up tilt table test were compared with changes in heart rate and blood pressure. The DACL was calculated for the five minutes before tilt, for periods $0-5,5-10$, and 10-15 minutes in the upright position and for the five minutes after returning to the supine position. Analysis was also performed at one minute intervals to investigate the momentary changes in heart rate and DACL during the study period.

\section{STATISTICAL METHODS}

Data are expressed as means and standard deviations (in text and tables) and medians (in tables). Friedman's test for repeated measurements was used for statistical evaluation of the whole group. Wilcoxon's signed rank test was used to evaluate the significance of changes within the groups. The Spearman rank correlation test was used for statistical evaluation of correlation coefficients. Results were considered significant at $\mathrm{p}<0.05$.

\section{Results}

CHANGES IN HEART RATE, DACL, AND BLOOD PRESSURE

Two patients were excluded because of syncope and multifocal atrial tachycardia (table 1). 
Table 2 Effects of head up tilt table test in patients with chronic atrial fibrillation

\begin{tabular}{llllll}
\hline Variable & $\begin{array}{l}\text { 0-5 minutes } \\
\text { before tilt }\end{array}$ & $\begin{array}{l}\text { 0-5 minutes } \\
\text { upright position }\end{array}$ & $\begin{array}{l}5-10 \text { minutes } \\
\text { upright position }\end{array}$ & $\begin{array}{l}\text { 10-15 minutes } \\
\text { upright position }\end{array}$ & $\begin{array}{l}\text { 0-5 minutes } \\
\text { after tilt }\end{array}$ \\
\hline HR (beats/min) & $91(18.1), 94$ & $106(25.8), 101^{\star \star}$ & $107(27.5), 102$ & $109(31.0), 102$ & $93(20.5), 96^{\star \star}$ \\
SBP (mm Hg) & $129(17.3), 132$ & $126(22.8), 120$ & $126(21.4), 120$ & $126(21.1), 125$ & $128(20.9), 125$ \\
DBP (mm Hg) & $91(12.5), 95$ & $87(13.0), 82$ & $89(12.4), 87$ & $88(12.8), 85$ & $90(13.2), 85$ \\
DACL (ms) & $160(18.6), 161$ & $150(12.8), 148^{\star \star}$ & $148(14.7), 147$ & $147(15.5), 146$ & $154(18.5), 152^{\star \star}$ \\
\hline
\end{tabular}

Values are presented as mean (SD), median.

${ }^{\star} \mathrm{p}<0.05,{ }^{\star \star} \mathrm{p}<0.01$, all other changes non-significant. Statistical comparison was with the preceding value.

DACL, dominant atrial cycle length; DBP, diastolic blood pressure; HR, heart rate; SBP, systolic blood pressure.

One patient fainted after nine minutes in the upright position (fig 2). The tilt test was immediately interrupted and the patient was returned to the supine position, making it impossible to follow the study protocol. After recordings were performed it became obvious from the surface ECG that one patient did not have chronic atrial fibrillation, but rather a multifocal atrial tachycardia; this also resulted in exclusion from the study. Calculations were made on the basis of the remaining 12 patients. In the supine position before tilt the DACL had a mean (SD) value of 160 (18.6) $\mathrm{ms}$ and ranged from 114 to $196 \mathrm{~ms}$. A significant decrease in DACL was seen, from $160 \mathrm{~ms}$ at 0-5 minutes in the supine position before tilt, to $150 \mathrm{~ms}$ at $0-5$ minutes in the upright position $(p<0.01)$ (table 2$)$. No significant changes in DACL were seen between $0-5$, 5-10, and 10-15 minutes in the upright position, whereas a decrease was seen in all three periods compared with the supine position before tilt $(p<0.01)$. The DACL increased from $147 \mathrm{~ms}$ at $10-15$ minutes in the upright position to $154 \mathrm{~ms}(\mathrm{p}<0.01)$ at $0-5$ minutes in the supine position after tilt. Mean (SD) heart rate was 91 (18.1) beats/min and ranged from 62 to 119 beats/min in the supine position before start of tilt. Mean heart rate increased from 91 beats/min at $0-5$ minutes in the supine position before tilt to 106 beats $/ \mathrm{min}$ at $0-5$ minutes in the upright position $(p<0.01)$ (table 2). No significant changes in

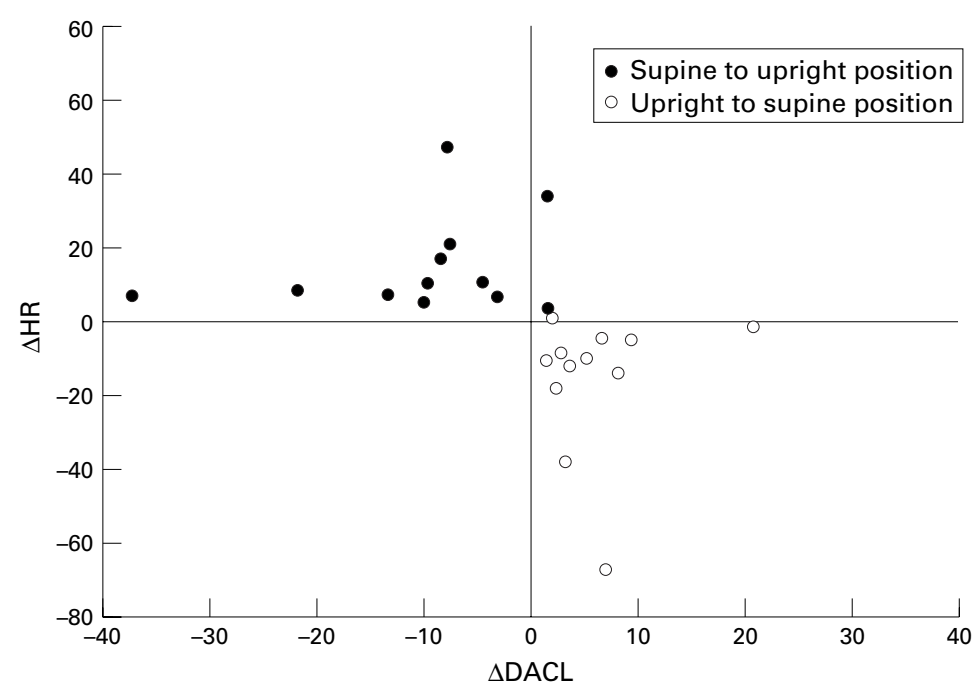

Figure 3 There were indications of an inverse relation between dominant atrial cycle length (DACL) and heart rate (HR) when the supine position before tilt was compared with the upright position, and when the upright position was compared with the supine position after tilt (correlation coefficient $=-0.71, p<0.001$ ). The relation represents the different effects of increased and decreased sympathetic discharge on the atrial cycle length and AV nodal conduction time, suggesting that the effects of increased sympathetic discharge were superior to the effects of vagal withdrawal on atrial refractoriness. heart rate were observed between $0-5,5-10$, and 10-15 minutes in the upright position, and heart rate was increased in all three cases compared with the supine position before tilt $(p<0.01)$. Mean heart rate decreased from 109 beats/min at $10-15$ minutes in the upright position to 93 beats/min after returning to the supine position $(\mathrm{p}<0.01)$. No significant changes in systolic or diastolic blood pressure were seen (table 2).

RELATION BETWEEN DACL AND HEART RATE DURING THE TILT TABLE TEST

There were indications of an inverse relation between DACL (that is, the difference between the DACL in the periods being compared) and heart rate when $0-5$ minutes in the supine position before tilt was compared with $0-5$ minutes in the upright position (fig 3). Similarly, there were indications of an opposite, inverse relation between DACL and heart rate when the 10-15 minutes period in the upright position was compared with the $0-5$ minutes period in the supine position after tilt (correlation coefficient $=-0.71, \mathrm{p}<0.001)$.

\section{Discussion}

THE DOMINANT ATRIAL CYCLE LENGTH IN

CHRONIC ATRIAL FIBRILLATION

We have recently shown that the atrial component in the surface ECG from patients with chronic atrial fibrillation contains valuable information on the magnitude and the dynamics of the atrial cycle length. ${ }^{25}$ The atrial component of the surface ECG can be extracted using a new method called FAFECG (frequency analysis of fibrillatory ECG), which includes time averaging and spectral analysis techniques. Using magnetic resonance imaging it was deduced that the right atrium is responsible for a major contribution to the $f$ waves in lead V1. Furthermore, it was shown that the spatial mean intracardiac cycle length in the right atrium is closely related to the DACL, measured at lead V1. Since earlier studies have verified that local fibrillation cycle lengths are closely related to the refractory period, the DACL at lead V1 may be used as an index of the right atrial refractoriness. ${ }^{26-28}$ Further support for the use of DACL as an index of right atrial refractoriness has been obtained by studying the effects of DL-sotalol, a well known class III antiarrhythmic drug. The changes in DACL were of the same direction and magnitude as the changes in atrial refractoriness expected with this intervention during sinus rhythm. ${ }^{25}$ 


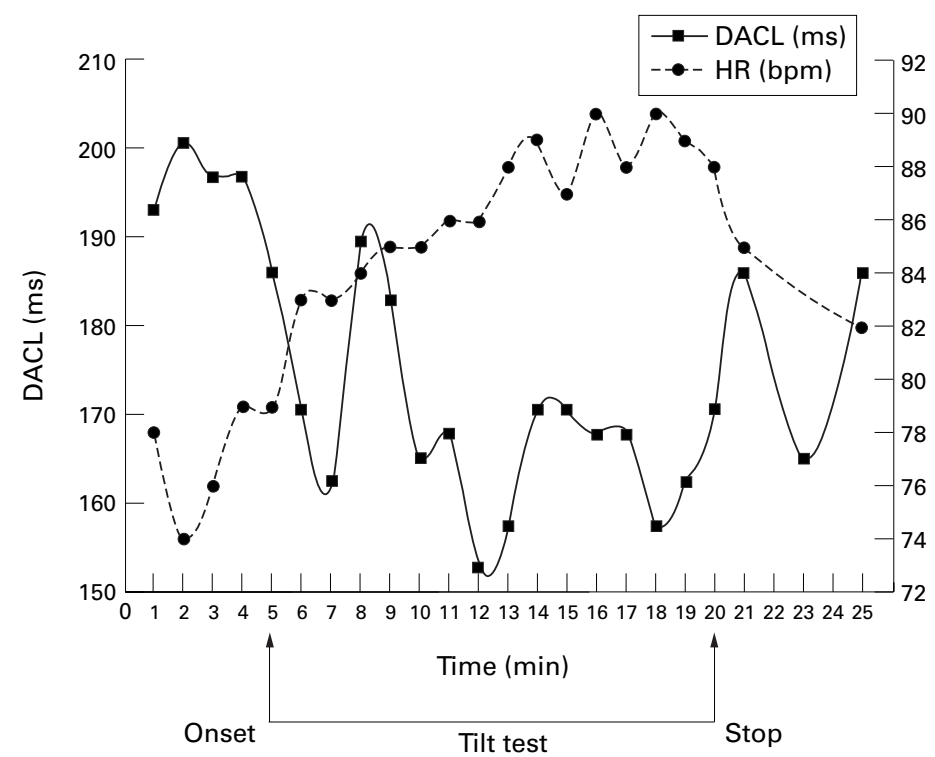

Figure 4 A typical patient example, illustrating one minute changes in heart rate (HR) and dominant atrial cycle length (DACL) during the tilt procedure. An increased sympathetic discharge and withdrawal of vagal activity is known to be the physiological response to the head up tilt table test. Increased sympathetic activity during chronic atrial fibrillation may favour the persistence of the arrhythmia and probably reduces the chances for a resumption of sinus rhythm.

EFFECTS OF AUTONOMIC NERVOUS DISCHARGE ON ATRIAL REFRACTORINESS AND CONDUCTION Limited information is available on the effects of the autonomic nervous system on atrial refractoriness and conduction in chronic atrial fibrillation. Stimulation of either limb of the autonomic nervous system will reduce the action potential duration, whereas the refractory period seems to be affected most by vagal discharge. ${ }^{67}$ An increased vagal discharge has been shown to decrease the refractory period by increasing the muscarinic acetylcholine receptor operated potassium current $\left(\mathrm{I}_{\mathrm{K}(\mathrm{Ach})}\right) .^{29}$ At the cellular level, sympathetic discharge will stimulate $\beta$ receptors in the atrial muscle. From studies on atrial pacemaker cells it has been shown that increased $\beta$ receptor stimulation results in an activation of $G$ protein and production of cAMP, which subsequently activates a protein kinase. ${ }^{30} 31$ Activation of the protein kinase will finally result in phosphorylation of the L-type calcium channel and the delayed rectifier potassium channel. ${ }^{32} 33$ The effect of an increased channel phosphorylation is an increased ionic current through these channels. The overall effect will be a decreased refractory period in the atrial muscle. It has been shown that dispersion of atrial refractoriness during chronic atrial fibrillation is increased by acetylcholine as well as by complete autonomic blockade. ${ }^{34}$ The mechanism of this action is complex, as increased vagal discharge is known to cause hyperpolarisation of the atrial muscle. ${ }^{35}$

In normal atrial muscle during sinus rhythm it has been shown that increased sympathetic discharge may increase atrial conduction velocity and that $\beta$ adrenergic blockade decreases atrial conduction velocity. ${ }^{136}$ Indirect evidence for this has been provided by the autonomic stimulation and blockade, respectively, of signal averaged $\mathrm{P}$ wave duration, a proposed indicator of atrial conduction properties. $^{4}$ Increased vagal activity has been shown to cause a slowing of intra-atrial conduction, whereas a decreased vagal discharge might increase it. ${ }^{2} 377$ Thus the effects of sympathetic and vagal discharge in atrial muscle are synergistic on the refractory period and antagonistic on conduction velocity.

\section{PHYSIOLOGICAL EFFECTS OF THE HEAD UP TILT} TABLE TEST

Upright tilt is a physiological stimulus that is associated with increased sympathetic tone and withdrawal of vagal activity. ${ }^{38}{ }^{39}$ An increase in plasma catecholamines has been observed after tilting and it has been suggested that the mechanism for increased sympathetic tone is increased $\beta$ adrenergic neural activity. ${ }^{38}$ The head up tilt table test is also associated with parasympathetic withdrawal. ${ }^{39}$

In this study, one patient was excluded because of syncope. Failure to decrease parasympathetic tone in the upright position has been shown to be a predictor of vasodepressor syncope. ${ }^{40}$ The results of heart rate and DACL in the syncope patient illustrated in fig 2 indicate the different actions of increased vagal activity on AV nodal and atrial cells. The AV nodal conduction time is increased, whereas the DACL is decreased, suggesting decreased atrial refractoriness. ${ }^{41}$

EFFECTS OF HEAD UP TILT TABLE TEST ON HEART RATE, DACL, AND BLOOD PRESSURE IN CHRONIC ATRIAL FIBRILLATION

A significant increase in heart rate was seen, from 91 beats $/ \mathrm{min}$ in the supine position before tilt to 106 beats/min in the upright position, which is compatible with an increased sympathetic discharge and a withdrawal of vagal activity. ${ }^{38-40}$ An increase in sympathetic activity is known to increase heart rate by decreasing the AV nodal conduction time. ${ }^{42}$ Furthermore, the heart rate was significantly decreased, from 109 to 93 beats $/ \mathrm{min}$, after return to the supine position. The decrease in heart rate in the supine position after tilt indicates a decrease in sympathetic discharge and possibly a revival of vagal activity.

DACL decreased significantly, from $160 \mathrm{~ms}$ in the supine position before tilt to $150 \mathrm{~ms}$ in the upright position (table 2). Furthermore, DACL increased significantly, from $147 \mathrm{~ms}$ in the upright position to $154 \mathrm{~ms}$ after returning to the supine position. The electrophysiological effects of the tilt test in this study correlate with the results from invasive electrophysiological studies performed with the head up tilt table test during sinus rhythm. ${ }^{36}$ The changes in DACL and heart rate from a typical patient are shown in fig 4. The major effect of upright posture seems to be decreased refractoriness of the atrial muscle, evidenced by a decrease in the DACL. The changes in DACL indicate that the effects of increased sympathetic discharge are dominant over those of decreased vagal activity in the upright position. The opposite relation was observed when comparing DACL and heart rate in the upright position with values obtained in the supine position after tilt (fig 
3). When the theoretical wavelength decreases during tilt, a smaller area of the atrium will be sufficient to set up a reentrant circuit, a circumstance unfavourable for the chronic atrial fibrillation patient. $^{43}$ The predominance of sympathetic discharge in the upright position may therefore increase the tendency to reentry and decrease the possibility of resumption of sinus rhythm.

The systolic and diastolic blood pressures were not significantly changed during the tilt procedure (table 2). The irregular and rapid heart rate seen during chronic atrial fibrillation will produce varying diastolic intervals and thereby varying stroke volumes, interfering with the filling of the arterial tree and consequently with the pulse pressure. ${ }^{45}$ The results for systolic and diastolic blood pressures in this study were probably affected by the difficulties associated with measuring blood pressure manually during chronic atrial fibrillation.

DISTURBANCES IN AUTONOMIC TONE MAY CONTRIBUTE TO BOTH INDUCTION AND PERSISTENCE OF CHRONIC ATRIAL FIBRILLATION It is well known that atrial fibrillation can be induced by increased discharge from either autonomic nervous system limb. ${ }^{7-12}$ The specific mechanism for this action is unknown, although decreased atrial refractoriness, automatism, and triggered activity have been proposed to be involved. As atrial fibrillation is induced, the asynchrony of atrial and ventricular muscle contraction often decreases the cardiac output and thereby the arterial blood pressure. ${ }^{45}$ These changes will produce a reflex increase in sympathetic discharge that will decrease the DACL and increase the heart rate, as shown in this study. The decrease in DACL, suggested to represent atrial refractoriness, will be unfavourable for the relation between atrial size and the number of concomitant reentrant wavelets possible. ${ }^{434}$ Consequently, increased activity of either autonomic nervous system limb could favour the persistence of chronic atrial fibrillation by reducing atrial refractoriness and decreasing the possibility of resumption of sinus rhythm.

CONCLUSIONS

We conclude that upright position, known to induce increased sympathetic discharge and withdrawal of vagal activity, increases the heart rate and decreases the DACL in chronic atrial fibrillation and that these changes are reversible after returning to the supine position. Furthermore, there are indications of an inverse relation between DACL and heart rate when comparing upright and supine position, indicating that the effects of increased sympathetic discharge are dominant over the effects of vagal withdrawal. Thus a reflex increase in sympathetic activity after induction of atrial fibrillation may favour the persistence of the arrhythmia.

This work was supported by grants from the Swedish Heart Lung Foundation and the Medical Faculty, University of Lund, Sweden.

1 Hoffman BF, Singer DH. Physiological and clinical aspects of beta adrenergic blockade. Ann NY Acad Sci of beta adrenergic
2 Rosenshtraukh LV, Zaitsev AV, Fast VG, et al. Vagally induced depression of impulse propagation as a cause of induced depression of impulse propagation as a

3 Dhingra RC, Amat-Y-Leon F, Wyndham C, et al. Electrophysiologic effects of atropine on human sinus node and atrium. Am $\mathcal{f}$ Cardiol 1976;38:429-34

4 Cheema AN, Ahmed MW, Kadish AH, et al. Effects of autonomic stimulation and blockade on signal-averaged $\mathrm{P}$ wave duration. I Am Coll Cardiol 1995;26:497-502.

5 Shimizu W, Tsuchioka Y, Karakawa S, et al. Differential effect of pharmacological autonomic blockade on some electrophysiological properties of the human ventricle and electrophysiological properties of

6 Takei M, Furukawa Y, Narita M, et al. Synergistic nonuniform shortening of atrial refractory period induced by autonomic stimulation. Am f Physiol 1991;261:H198893.

7 Euler DE, Scanlon PJ. Acetylcholine release by a stimulus train lowers atrial fibrillation threshold. Am f Physiol 1987; 253:H863-8.

8 Coumel P. Clinical approach to paroxysmal atrial fibrillation. Clin Cardiol 1990;13:209-12.

9 Coumel P, Attuel P, Leclerq JF, et al. Arythmies auriculaires d'origine vagale ou catécholergique: effets comparés du traitment bêtabloquant et phénomène de d'échappement. Arch Mal Coeur 1982;75:373-87.

10 Coumel P. Neural aspects of paroxysmal atrial fibrillation. In: Falk RH, Podrid PJ, eds. Atrial fibrillation: mechanisms and management. New York: Raven Press, 1992:109-25.

11 Coumel P, Attuel P, Lavallée JP, et al. Syndrome d'arythmie auriculaire d'origine vagale. Arch Mal Coeur 1978;71:64556.

12 Charpentier F, Drouin E, Gauthier C, et al. Early after depolarisations and trigged activity: mechanisms and autonomic regulation. Fundam Clin Pharmacol 1993;7:39-49.

13 Mary-Rabine L, Albert A, Pham TD, et al. The relationship of human atrial cellular electrophysiology to clinical function and ultrastructure. Circ Res 1983;52:188-99.

14 Ten Eick RE, Singer DH. Electrophysiological properties of diseased human atrium. I. Low diastolic potential and altered cellular response to potassium. Circ Res 1979;44: 545-57.

15 Hordof AJ, Edie R, Malm JR, et al. Electrophysiologic properties and response to pharmacologic agents of fibers from diseased human atria. Circulation 1976;54:774-9.

16 McCullough JR, Baumgarten CM, Singer DH. Intra- and extracellular potassium activities and the potassium extracellular potassium activities and the potassium cells. F Mol Cell Cardiol 1987;19:477-86.

17 Sako H, Imanishi S, Arita M, et al. Unaffected electrogenic $\mathrm{Na}-\mathrm{K}$ pump activity in diseased human atrial fibers, as assessed by intracellular $\mathrm{K}^{+}$activity. Fpn f Physiol 1989;39: 873-90.

18 Imanishi S, Arita $M$. Factors related to the low resting membrane potentials of diseased human atrial muscles. $7 p n$ F Physiol 1987;37:393-410.

19 Lee YS. Pathophysiological mechanisms of altered transmembrane potentials in diseased human atria. $\mathcal{F}$ Electrocardiol 1986;19:41-50.

20 Wijffels MCEF, Kirchof CJHJ, Dorland R, et al. Atrial fibrillation begets atrial fibrillation: a study in awake fibrillation begets atrial fibrillation: a study in awake
chronically instrumented goats. Circulation 1995;92:195468 .

21 Goette A, Honeycutt C, Langberg JJ. Electrical remodeling in atrial fibrillation: time course and mechanisms. Circulation 1996;11:2968-73.

22 Tieleman RG, De Langen CDJ, Van Gelder IC, et al. . Verapamil reduces tachycardia-induced electrical remodeling of the atria. Circulation 1997;95:1945-53.

23 Tielman RG, Crijns HJGM, van Gelder IC, et al. A clinical illustration of reduction of electrical remodeling by the use of intracellular calcium lowering drugs during AF [abstract]. PACE 1997;20:1142.

24 Coumel P, Hermida JS, Wennerblom B, et al. Heart rate variability in myocardial hypertrophy and heart failure, and the effects of beta-blocking therapy: a non-spectral analysis of heart rate oscillations. Eur Heart f 1991;12:412-22.

25 Holm M, Pehrson S, Ingemansson M, et al. Non-invasive assessment of the atrial cycle length during atrial fibrillation in man: Introducing, validating and illustrating a new ECG method. Cardiovasc Res [in press].

26 Lammers WJEP, Allessie MA, Rensma PL, et al. The use of fibrillation cycle length to determine spatial dispersion in electrophysiological properties and to characterize the underlying mechanism of fibrillation. New Trends in Arrhythmias 1986;2:109-12.

27 Capucci A, Biffi M, Boriani G, et al. Dynamic electrophysiological behaviour of human atria during paroxysmal atrial ological behaviour of human atria during parc

28 Kim K-B, Rodefeld MD, Schuessler RB, et al. Relationship between local atrial fibrillation interval and refractory period in the isolated canine atrium. Circulation 1996;94: 2961-7.

29 Kaibara M, Nakajima $T$, Irisawa $H$, et al. Regulation of spontaneous opening of muscarinic $\mathrm{K}^{+}$channels in rabbit atrium. F Physiol (Lond) 1991;433:589-613.

30 DiFrancesco D, Tortota P. Direct activation of cardiac pacemaker channels by intracellular cyclic AMP. Nature 1991;351:145-7.

31 Yatani A, Okabe K, Codina J, et al. Heart rate regulation by $\mathrm{G}$ proteins acting on the cardiac pacemaker channel. Science 1990;249:1163-6. 
32 Kameyama M, Hescheler F, Hoffmann F. On the mechanism of $\beta$-adrenergic regulation of the $\mathrm{Ca}$ channel in guinea pig heart. Pflügers Arch 1985;407:285-93.

33 Yazawa K, Kameyama M. Mechanisms of receptormediated modulation of the delayed outward potassium current in guinea-pig ventricular myocytes. F Physiol (Lond) 1990;421:135-50.

34 Rensma PL, Allessie MA, Lammers WJEP. Length of excitation wave and susceptibility to reentrant atrial arrhythmias in normal conscious dogs. Circ Res 1990;62:395-410

35 Boyett MR, Kodama I, Honjo $\mathrm{H}$, et al. Ionic basis of the chronotropic effect of acetylcholine on the rabbit sinoatrial node. Cardiovasc Res 1995;29:867-78.

36 Hermiller JB, Walker SS, Binkley PF, et al. The electrophysiologic effects of upright posture. Am Heart $\mathcal{7}$ 1984;108: 1250-4.

37 Yano K, Hirata T, Hirata M, et al. Effects of sympathetic and parasympathetic stimulation on the induction of atrial flut-
ter in dogs with aseptic pericarditis. $\mathscr{f} p n$ Heart $\mathcal{F}$ ter in dogs with

38 Sra J, Jazayeri M, Murthy V, et al. Sequential catecholamine changes during upright tilt: possible hormonal mechanisms responsible for pathogenesis of neurocardiogenic syncope [abstract]. F Am Coll Cardiol 1991;17:216A.

39 Ewing D, Hume L, Campbell I, et al. Autonomic mechanisms in the initial heart rate response to standing. $f$ Appl Physiol 1980;49:809-14.
40 Lippman N, Stein KM, Lerman BB. Failure to decrease parasympathetic tone during upright tilt predicts a positive tilt-table test. Am F Cardiol 1995;75:591-5.

41 Imaizumi S, Mazgalev T, Dreifus LS, et al. Morphological and electrophysiological correlates of atrioventricular nodal response to increased vagal activity. Circulation 1990;82: 951-64.

42 Prystowsky EN, Page RL. Electrophysiology and autonomic influences of the human atrioventricular node. In: Electrophysiology of the sino-atrial and atrioventricular nodes. New York: Alan R Liss, 1988:259-77.

43 Allessie MA, Rensma PL, Lammers WJEP, et al. The role of refractoriness, conduction velocity, and wavelength in initiation of atrial fibrillation in normal conscious dogs. In: Attuel P, Coumel P, Janse MJ, eds. The atrium in health and Attuel P, Coumel P, Janse MJ, eds. The atrium in health and
disease. Mount Kisco, NY: Futura Publishing Co, 1989:27disease.

44 Rensma PL, Allessie MA, Lammers WJEP, et al. The length of the excitation wave as an index for the susceptibility to reentrant atrial arrhythmias. Circ Res 1988;62:395-410.

45 Naito M, David D, Michelson EL, et al. The hemodynamic consequences of cardiac arrhythmias: evaluation of the relative roles of abnormal atrioventricular sequencing, irregularity of ventricular rhythm and atrial fibrillation in a canine model. Am Heart f 1983;106:284-91. 